\title{
Introduction: Sailing along Intermedial Rivers
}

When considering the differences between Shakespeare's Othello and Verdi's operatic restyling Otello, following Arrigo Boito's drastically-reduced libretto, scholars have asked how the opera was fully able to set to music Shakespeare's manipulation of words in the play-text. Examining how Verdi transforms Shakespeare's dramatic process into the medium of music, in "The Iagoization of Otello: A Study in Verdi's Musical Translation of Shakespeare's Linguistic Dramaturgy," Jeffrey Kurtzman explains that Verdi's solution was "to create a musical language for Iago, a different musical language for Otello, and then cause Iago's musical language to invade and transform that of Otello in a manner directly analogous to the way in which Shakespeare uses words” (72). Extrapolating this idea to the multiplicity of intermedial appropriations of Shakespeare's plays, we would say that a different language system is involved in representing the canonical plays and a different end-result is obtained. Bryan Reynolds describes this process in a unique manner in his Introduction to Intermedial Theater: Performance, Philosophy, Transversal Poetics, and the Future of Affect (2017):

The becomings- and comings-to-be-other, together, and through intermedial theatre, force-multiplied by its indeterminate structural propensities for affective emergences that exceed the artistic design of the theatre-media processes themselves, stimulate cascades of feedback-loops givings-way to feedforward-flows goings-elsewhere wondrously achieving transversality over the rainbow of composability. (Reynolds 1 )

While Reynolds uses the rainbow metaphor to express the "goings-elsewhere" of intermedial theatre, we would use the geographic metaphor of the river: just as a meandering river displays unexpected twists and turns, according to the geological structure of the terrain and, in our times, human intervention, intermedial adaptations of Shakespeare's plays are flowing along times and

* Ovidius University, Constanta, Romania; Zhejiang University, Hangzhou, China. 
cultures. Along the course there are many tributaries and partial blocks but the flow is what matters, and this is constant and progressive.

Why do we need to think critically about Shakespeare and intermedial / cross-cultural contacts? Just as it is no longer possible to speak of the media—or even a particular medium, such as television—as a singular entity, it is important to bring more specificity to issues of place, difference and reception in studying critically the intermedial Shakespearean appropriations. The critical study of appropriations of Shakespeare in various media is a dynamic field shaped through specific historical, economic and geographic contexts. While scholars now study a dizzying range of transformations of Shakespeare's plays through various media objects (print, television, film, music, advertising brands, the Internet, digital games, mobile phone applications) from multiple methodological and theoretical perspectives, they share a concern with understanding not just media but their changing role in social and power relations. Thomas Cartelli, in Reenacting Shakespeare in the Shakespeare Aftermath: The Intermedial Turn and Turn to Embodiment (2019), uses the term "mapping" (3) to trace "the intermedial turn and turn to embodiment" (4) that inform the shift in Shakespeare adaptation studies toward recontextualization, reformatting and media convergence. The reformatting of Shakespeare in different cultural, technical, and performance configurations can lead to a deeper understanding of how cultures recontextualize Shakespeare and the ways in which various media are involved in negotiating these transactions.

This volume provides a toolbox for making sense of Shakespeare studies in relation to media culture by placing various intermedial representations as objects of critical inquiry. This is an attempt to situate the shifting concerns of media studies and Shakespeare within different historical, geographic, and cultural contexts. These contexts are the backdrop for distant (but overlapping) "types" of Shakespeare adaptations in various media, broadly characterized as print media (translations, for example), theatrical productions, practical applications of teaching Shakespeare through Digital Humanities, or movie and novelistic adaptations. We would take the different scholarly contributions to Shakespeare and intermedial adaptations (by scholars from Canada, the US, China, Italy, Slovakia, and Romania) as “discursive formations” (Spiegel 1213). Following Michel Foucault's Archaeology of Knowledge, Spiegel suggests that different ways of interpreting media critically constitute the "truths" available to scholars. Spiegel writes that these "discursive formations" are "limited groups of statements that are spoken at a specific historical moment" (Spiegel 1213). The specific historical moment of the 2020s brings into contact a heteroglossia of encounters concerning Shakespearean appropriations. Almost half of these essays are about Shakespeare in translation and performance in China, which suggests the surging interest in Shakespeare in Asia. Europe is also wellrepresented in this volume, as are Canada and the United States of America. 
These essays are connection points emerging from the kind of scholarly geography that knows no borders or ideological constraints.

Many concerns of contemporary media and performance studies are actually addressed in Shakespeare's plays, among them the representation of reality, the role of the audience in creating meaning and the nature of dramatic illusion. Shakespeare creates an intriguing multiplicity of meta-theatrical devices, such as plays-within-the plays (A Midsummer Night's Dream, Hamlet, or the Induction in The Taming of the Shrew), but also parodic roles of directors (such as Peter Quince in A Midsummer Night's Dream, who assigns roles, rehearses the cast and adapts from page to stage the play-text he has written; or Prospero in The Tempest, who manipulates the characters as a master puppeteer through the spirit Ariel). Moreover, there are even more complex ways in which Shakespeare inscribes the mechanism of textual transcendence and the three main steps of stage adaptation - conception, presentation, and reception-within the play-text itself. Shakespeare gives special attention to intra- and inter-medial procedures inscribed throughout the play-text, which anticipates a series of theoretical premises devised by contemporary media and performance studies. For example, in adapting intermedially Ovid's Metamorphoses in Titus Andronicus, Shakespeare conflates stories and creates a hybridized dramatic space attuned to dynamic theatrical configurations. Shakespeare knew that any text, transposed into a new historical and geographic context, required transformation. Whenever he adapted an ancient verse narrative (such as Ovid), a story of his own or a foreign culture, or Holinshed's English history and Plutarch's Lives, Shakespeare introduced changes of perspective, ambience, atmosphere, plot, characterization, according to the demands of the theatre of his time. Moreover, Shakespeare also knew that the transposition of a play-text from page to stage (or from written text to playscript) is a complex intermedial transaction, involving acts of mediation, interpretation and representation.

The contributors to this special issue of Multicultural Shakespeare share a broad interest in theatrical practices and intermedial adaptations of Shakespeare's plays. Essays range from pedagogical applications of Shakespeare in the new medium of Digital Humanities (Makaryk and Hemingway), to an interview with a theatre director who staged Cry Havoc and She Wolf (Pennacchia interviewing Stephan Wolfert), and analyses of theatrical productions (in Romania, Matei-Chesnoiu, and in China, Renfang Tang). Studies of cross-cultural and intermedial appropriations of Shakespeare's plays continue with an analysis of the translations of Charles and Mary Lamb's Tales from Shakespeare in China (Yun-fang Dai), the development of Marxist Shakespeare criticism in China (Wei Zhang), and Shakespeare in Taiwan (Yu Sun and Longhai Zhang). Dana Percec discusses the tension between Shakespeare's plays and narrative adaptations in contemporary novels and, finally, an analysis of recent filmic appropriations of Shakespeare's plays connects The Tempest with popular culture (Jana Wild). 
In their opening paper Irena R. Makaryk and Ann Hemingway outline an archival-digital pilot launched in 2015 at the University of Ottawa, Canada. It situates the Shakespeare in Canada project, a productive collaboration between faculty, libraries, archival institutions, and museums, in its historical context; details its early offering and subsequent iterations; and surveys the assumptions, challenges, surprises, and pleasures of introducing students to archival sources and to acquiring digital literacy. Participating students form "their Canadian identities through the prism of Shakespeare" (10) and develop a personalrather than universal-relationship with the Bard. As a fruit of their archival research, the digital-age students opened up a new field of inquiry, Shakespeare in the Arctic (11-12). The old "technology" of archives, museums, and libraries turns out to be "not only the impetus for creative and historical awakenings but also the rich medium with which students can still fall in love" (15).

Then Maddalena Pennacchia contributes an edited interview with Stephan Wolfert, American actor and playwright, who discusses his pluriawarded play, Cry Havoc, a one-man show he has been performing since 2012, with a most recent performance hosted at the Roma Tre Palladium Theatre during the International Conference ESRA 2019 in July. Wolfert rewrites and performs the story of his life by re-enacting Shakespeare's many military veterans: from Richard III to Antony, from Coriolanus to Henry V, et al.; by doing so he promotes Shakespeare's role as a psychotherapist who treats post-traumatic stress in military veterans. For Wolfert, the theatre effects a therapeutic catharsis especially in the US veterans who find it difficult to readjust to civilian rules after returning home. In particular, Shakespeare's blank verse is written "in the natural human rhythm of heartbeat and breath" (5); "by speaking in the verse rhythm and using Shakespeare's texts, we begin to turn on parts of the brain that had gone offline due to trauma" (7). Wolfert's "communalization of trauma" (6) via the ancient medium of the theatre works physiologically as well as aesthetically.

Wolfert's interview is followed by a pair of papers on theatrical productions. Monica Matei-Chesnoiu analyses the 2001 Romanian production of Hamlet directed by Vlad Mugur at the Cluj National Theatre (Romania) from the perspective of geocriticism and spatial literary studies. After the vicissitudes of Communism, the belated production abbreviates the topic of death to its bare essence, just as a map condenses space, in the form of "literary cartography," exploring the exposed depth of human existence. The swan-song production examines the human condition and the artist's place in the world while everything happens on the edge of nothingness. The director's own death before the opening night of the production ties Shakespeare's Hamlet with existential issues in an even deeper way than the play itself. Renfang Tang's paper studies two huaju performances of Shakespeare, Coriolanus (2007) and King Lear (2006), as cases of cultural exchange between East and West that integrate 
Shakespeare into contemporary Chinese culture and politics. These Chinese huaju adaptations demonstrate how (intercultural) identity is constructed through the subjectivity and iconicity of Shakespeare's characters and the performativity of Shakespeare's texts.

The reception of Shakespeare in China is the focal interest of the next group of three papers. Yun-fang Dai explains why Charles and Mary Lamb's Tales from Shakespeare was so popular before Shakespeare's original texts were translated. She investigates by citing archival materials how the Lambs' Tales might have reached China at the beginning of the nineteenth century through sinologist Thomas Manning's correspondence with Charles Lamb. Dai's work sheds light on a dark corner of the early cultural reception of Shakespeare in China. Wei Zhang traces the vicissitudes of Marxist Shakespearean criticism in China since the 1930s by chronicling the history in three periods and discussing the contributions of ten representative scholars including Mao Dun and Wang Yuanhua, who adopted the basic principles and methods of Marxism to elaborate on Shakespeare's works. Yu Sun and Longhai Zhang survey the intricate relationship in the history of Shakespeare studies in mainland China and Taiwan from a developmental perspective. Shakespeare studies in mainland China and Taiwan evolved from the same origin. A new performing medium, Shake-xiqu, a hybrid of Shakespeare and traditional Chinese theatre, enables theatrical practitioners on both sides of the Taiwan Strait to explore new possibilities of Chinese Shakespeares.

Dana Percec interprets three novels in the Shakespeare Re-told Hogarth series, namely Jeanette Winterson's Gap of Time (2016), Margaret Atwood's Hag-Seed (2016), and Edward St. Aubyn's Dunbar (2018), as rewritings of Shakespeare in the new media environments, respectively of The Winter's Tale, The Tempest, and King Lear. Shakespeare's versatile uses, in video games, in alternative, unconventional educational environments and in the audio-visual, blend successfully particular elements of Anglo-American culture with universal and atemporal themes of love and loss, creation and destruction, death and rebirth. For Jana B. Wild, the blockbuster musical comedy Mamma mia can be seen as a soft and slightly ironical feminist rewriting of Shakespeare's The Tempest. Set on a small Greek island, idyllic and exotic, the film offers a contemporary romantic story with new/reversed roles in terms of gender, parenthood, sexuality, marriage and age, pointing to an entirely different cultural paradigm from the early modern one. Knowledge of Shakespeare enhances the appreciation of the feminist filmic adaptation.

Sailing along the intermedial rivers, our reader may enjoy various views of past and present, East and West. Even better, s/he might see reflections of her/himself in the rivers. Other than communal or individual enjoyment and reflection, what is the use of literature in this digital age of globalisation? 


\section{WORKS CITED}

Cartelli, Thomas. Reenacting Shakespeare in the Shakespeare Aftermath: The Intermedial Turn and Turn to Embodiment. New York: Palgrave Macmillan, 2019.

Foucault, Michel. The Archaeology of Knowledge. Trans. A. M. Sheridan Smith. New York: Pantheon, 1972.

Kurtzman, Jeffrey. "The Iagoization of Otello: A Study in Verdi’s Musical Translation of Shakespeare's Linguistic Dramaturgy." In Sonic Transformations of Literary Texts: From Program Music to Musical Ekphrasis. Nine Essays edited by Siglind Bruhn. Interplay: Music in Interdisciplinary Dialogue 6 (2008): 69-101. Gen. ed. Magnar Breivick and Siglind Bruhn. Hillsdale, NY: Pendragon Press, 2008.

Reynolds, Bryan. "Introduction: Formal Matters." Intermedial Theater: Performance, Philosophy, Transversal Poetics, and the Future of Affect. Ed. Bryan Reynolds. Palgrave Studies in Performance and Technology. New York: Palgrave Macmillan, 2017. 1-4.

Spiegel, Lynn. "Theorizing the Bachelorette: 'Waves' of Feminist Media Studies.” Signs: Journal of Women in Culture and Society 30/1 (2004): 1209-1221. 